\title{
Impressions of Hazmat Suits Based on Color
}

\author{
Yoshiko Nishizawa ${ }^{1 *}$, Keiko Aizu1, Kohsei Kudo', Sonoko Takase1, Ryoko Tsuchiya ${ }^{2}$, \\ Yuka Noto1, Chiaki Kitamiya', Yoichiro Hosokawa1
}

${ }^{1}$ Hirosaki University Graduate School of Health Sciences, Hirosaki, Japan

${ }^{2}$ Hirosaki University Hospital, Hirosaki, Japan

Email: *yoshiko@hirosaki-u.ac.jp

How to cite this paper: Nishizawa, Y., Aizu, K., Kudo, K., Takase, S., Tsuchiya, R., Noto, Y., Kitamiya, C. and Hosokawa, Y. (2018) Impressions of Hazmat Suits Based on Color. Open Journal of Nursing, 8, 879-888.

https://doi.org/10.4236/ojn.2018.812066

Received: November 14, 2018

Accepted: December 17, 2018

Published: December 20, 2018

Copyright $\odot 2018$ by authors and Scientific Research Publishing Inc. This work is licensed under the Creative Commons Attribution International License (CC BY 4.0).

http://creativecommons.org/licenses/by/4.0/

\begin{abstract}
Background: Commonly, skin and clothing surface contamination screening (radiation survey) is performed for residents of an area to confirm the levels of residual contamination after nuclear power disasters. Examiners for such a screening often wear white radiation hazmat suits. However, it has been reported that examinees tend to feel tension or anxiety. In this study, we focus on the color of the radiation hazmat suit as one measure to reduce residents' tension or anxiety. This study aims to determine the common conceptions of radiation hazmat suits based on color. Methods: An anonymous self-administered questionnaire survey was conducted with a total of 262 participants consisting of nursing students, administrative staff of a university, general citizens, and mothers raising their children in the Tohoku region in Japan. The common impressions of radiation hazmat suits, which are typically white, were measured using the Multiple Affective States Scale. This scale can measure the affective state brought about by clothing. The color of white (W) was defined as a standard color commonly used for hazmat suits; in order to determine the common impressions of radiation hazmat suits based on color, the following additional colors were shown to the participants: salmon pink (P), ivory (I), and light green (G). Results: There were no sex differences regarding common impressions of radiation hazmat suits. For white radiation hazmat suits, a high score reflecting the characteristic of "capable" was obtained, while the scores for "cheerful" and "calm" were low, and those for "depressed" and "tense" were high. The colors that showed the highest score for "calm" as a positive affirmative state were I and P. W and P reflected a high "ashamed" score, and the "tense" score for G was higher for the participants in their 20s than for those in their 30s and older. Conclusions: Results show that the color of hazmat suits provokes far greater feelings of anxiety and tension on participants than previously thought. Radiation hazmat suits may be further improved based on the results of this study.
\end{abstract}




\section{Keywords}

Radiation, Hazmat Suit, Color, Impression

\section{Introduction}

A hazmat suit is clothing used to protect a body from at least one kind of critical adverse factor (hazard). These suits are used in a variety of settings, and the category refers to clothing used to protect a body from exposure to radiant heat caused by high temperatures and flames at the time of a disaster, chemical protection suits to safely handle chemical agents, and suits that protect against physical and mechanical irritations at work. Thus, these types of suits are common for covering workers' entire bodies and ensuring safety. However, these clothes place a big burden on the workers' bodies due to heat stress. To relieve this stress as much as possible, many studies have been conducted on how to improve hazmat suits by establishing certain conditions such as the work environment; typically, these studies primarily use physiological indicators such as heart rate or the temperature of the rectum [1]-[6].

In the health care setting, hazmat suits are commonly used to protect care providers from infection when they take care of patients, in order to prevent the spread of infection at an outbreak. For example, hazmat suits are used when providers treat patients with new strains of influenza or Ebola hemorrhagic fever. Because of the rapid progress of radiation therapy, many tests using radiation are frequently performed in medical institutions. The radiation can be measured but it is invisible, so it is necessary for health professionals to understand the characteristics of radiation when they engage in their tasks. For example, when conducting X-rays, health professionals protect their bodies from exposure to radiation using a protective pad.

Body surface contamination screenings (radiation surveys) are performed on residents of an area to confirm the levels of residual contamination after nuclear power disasters, which may cause dispersion of radioactive materials. Examiners and health professionals wear hazmat suits, a hat, mask, and goggles to protect them from radiation when they examine patients with suspected contamination and radiation exposure. In such cases, workers' bodies are placed under a great amount of stress because their suits must cover their entire bodies.

On the other hand, from the viewpoint of examinees, it can be said that the hazmat suit, hat, mask, and goggles elicit strong tension and anxiety from examinees. In addition, in our previous studies with nursing students and nurses [7], radiation hazmat suits were related to stronger negative feelings such as anxiety, fear, and a sense of being oppressed than were clothes commonly worn by people in the health professionals. Therefore, health professionals must try to reduce the examinees' feeling of tension and anxiety. However, there are few studies that have been undertaken from the viewpoint of examinees. 
In this study, we are focusing on the color of the radiation hazmat suits to improve these issues. Although white hazmat suits are conventionally used, it has been reported that health professionals wearing a white robe provide feelings of tension to patients, resulting in an elevation of blood pressure (i.e., white-coat hypertension) [8]. Okazaki et al. [9] also mentioned that blue or green uniforms for health professionals, instead of white robes, may improve the impressions toward physicians and nurses. It has also been reported that white nursing clothes provoke strong anxiety in children [10]. Radiation surveys are conducted among various age groups, from children to adults. We thought that examinees' tension and anxiety could be reduced by changing the color of hazmat suits. This study aims to determine the common impressions of radiation hazmat suits by color.

\section{Methods}

\subsection{Participants}

The participants comprised a total of 262 residents in the Tohoku region in Japan; they consisted of the nursing students and the administrative staff of A university, general citizens who had participated in a public lecture conducted in $B$ city, and mothers raising their children who participated in child care support projects held by $\mathrm{C}$ city. We did not use a power calculation or other justification for the sample size, because radiation in the target areas is a sensitive topic.

\subsection{Methods}

\subsubsection{Survey Method}

We recruited participants for the study in cooperation with researchers' explanation. An anonymous self-administered questionnaire survey was administered. The color of white (W) was defined as a standard color commonly used for hazmat suits, and the following colors, together with this standard color, were shown to the participants: salmon pink (P), ivory (I), and light green (G). These were selected as colors with relatively low negative reactions, which we decided based on the results of previous research [11] [12] and discussion among our colleagues.

\subsubsection{Attributes of the Participants}

The following items were investigated: sex, age, current place of residence, and prior experience of undergoing a radiation survey.

\subsubsection{Measurement of the Impressions of Hazmat Suits}

Four pictures of an examiner in different colored hazmat suits (Figure 1) were included in the questionnaire. White, as the standard color, was presented first, followed by the other colors in random order to prevent bias in the responses. The Multiple Affective States Scale [13] was used to examine the participants' impressions about hazmat suits. This scale can measure the affective state brought about by clothing. This scale comprised the following seven subscales: 


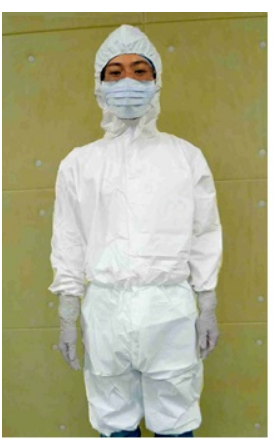

White

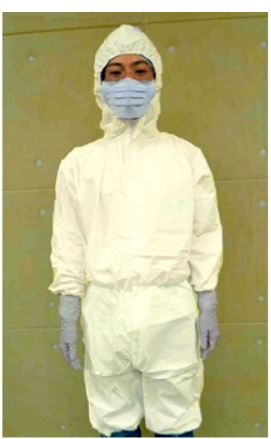

Ivory

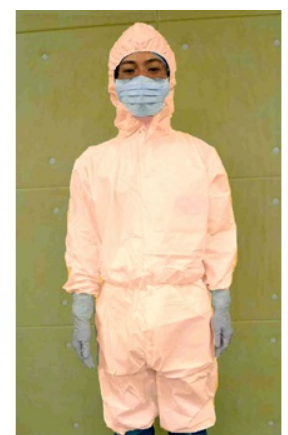

Salmon pink

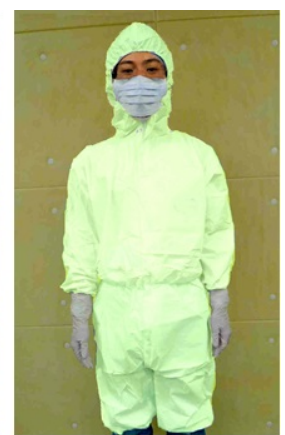

Light green

Figure 1. Photograph of a technician wearing a hazmat suit.

for positive affirmative states, 1) Cheerful, 2) Capable, 3) Confident, and 4) Calm; for negative affirmative states, 5) Depressed, 6) Ashamed, and 7) Tense. In this study, the following instruction was included: "How do you feel these clothes? Please circle the answer that best describes your mood and feelings when you see these clothes". We used a 4-point scale, where "1" meant "Does not describe at all" and "4" meant "Describes fully"; higher points indicate stronger feelings. The range of each scale was from 5 to 20 points. The Cronbach's alpha coefficient for this scale was $0.800-0.857$ [13], indicating high reliability. In this study, Cronbach's alpha coefficient was $0.896-0.935$, indicating high reliability.

\subsubsection{Ethical Considerations}

This study was approved by The Committee of Medical Ethics of Hirosaki University Graduate School of Health Sciences, Hirosaki, Japan (No.2016-016). We explained this study to the participants verbally and in written form and considered their responding to the questionnaire to be consent to participate.

\subsubsection{Survey Period}

This survey was performed between September 2016 and March 2017.

\subsubsection{Statistical Analysis}

For statistical analysis, the data were analyzed using PASW Statistics 21.0; a Mann-Whitney $U$ test and Friedman test were used to assess the data. A Bonferroni was used for multiple comparison. The level of significance was set at $\mathrm{p}<$ 0.05 .

\section{Results}

\subsection{Attributes of the Participants}

Among 262 participants, 258 agreed to participate in this survey and provided their responses (response rate, 98.5\%). Table 1 shows the details according to age groups. The participants consisted of 189 women and 69 men. The mean age of the participants was $22.6 \pm 8.75$ and $37.3 \pm 14.33$ years for women and men, respectively. A total of 27 participants had ever undergone a radiation survey 
Table 1. The number of participants according to sex and age.

\begin{tabular}{ccc}
\hline Age & Women & Men \\
\hline $10 s$ & 72 & 2 \\
$20 s$ & 97 & 20 \\
$30 s$ & 9 & 18 \\
$40 s$ & 3 & 10 \\
$50 s$ & 6 & 12 \\
$60 s$ & 2 & 7 \\
Total & 189 & 69 \\
\hline
\end{tabular}

while a total of 231 participants had not. The current place of residence of 254 participants was regions other than the Fukushima prefecture.

\subsection{Common Impressions of Hazmat Suits by Gender}

Generally, since there are sex differences in the impressions of colors, we compared the data according to sex as the first step. However, there were no significant sex differences in the four positive affirmative state categories or for the three negative affirmative state categories for all of the colors. However, for the hazmat suit in white, the "ashamed" score [quartile: median (25 percentile - 75 percentile)] tended to be slightly higher in the women's scores (10.0; 8.0 - 12.0) than the men's scores $(10.0 ; 6.0-12.0)(p<0.10)$. Similarly, for the hazmat suit in light green, the "calm" score tended to be slightly higher in the women's scores $(6.0 ; 5.0$ - 10.0) than the men's scores $(7.0 ; 5.0$ - 10.0) $(\mathrm{p}<0.10)$.

\subsection{Common Impressions of Hazmat Suits by Color (Table 2)}

Since there were no sex differences in the impression for radiation hazmat suits, the men's and women's score were analyzed together; Table 2 shows the results. The affective state reflecting a difference among the four colors was as follows: "cheerful", "capable", "calm", "depressed", and "tense" ( $p<0.000)$. Although the median "ashamed" score was 10.0 for all four colors, there was a statistically significant difference on the Friedman test $(\mathrm{p}<0.002)$. On that test, in the results of the multiple comparison, the "cheerful" score for $\mathrm{W}$ (quartile) was 6.0 (5.0 $10.0)$, which was lower than the scores for I, P, and G ( $p<0.001$; $p<0.000)$. However, the "capable" score for $\mathrm{W}$ was 10.0 (7.0 - 12.0), which was higher than the scores for I, P, and G $(p<0.000)$. The "calm" score for W was $5.0(5.0-8.0)$, which was lower than the scores for I and $\mathrm{P}(\mathrm{p}<0.001 ; \mathrm{p}<0.000)$; there was no difference from the scores for G. The "capable" score for P was 7.0 (5.0 - 10.0), which was higher than the scores for $\mathrm{G}(\mathrm{p}<0.008)$. The "depressed" score for $\mathrm{W}$ were $10.0(7.0$ - 12.0) and the "tense" scores for W were 15.0 (12.0 - 17.0); both of these scores were higher than those for I, P, and G $(p<0.000)$. The "ashamed" score for $\mathrm{W}$ was slightly higher than those scores for $\mathrm{I}(\mathrm{p}<0.009)$. However, $\mathrm{P}$ and $\mathrm{G}$ did not show a difference in comparison with $\mathrm{W}$ and $\mathrm{I}$. 
Table 2. Affirmative state scores by color.

\begin{tabular}{|c|c|c|c|c|c|c|}
\hline \multirow{2}{*}{ Multipl } & \multirow{2}{*}{ Affective States } & (1) White & (2) Ivory & (3) Salmon pink & (4) Light green & \multirow[t]{2}{*}{$\mathrm{p}$ value } \\
\hline & & $\begin{array}{lll}50 & 25 & 75\end{array}$ & $\begin{array}{lll}50 & 25 & 75\end{array}$ & $\begin{array}{lll}50 & 25 & 75\end{array}$ & $\begin{array}{lll}50 & 25 & 75\end{array}$ & \\
\hline \multirow{4}{*}{$\begin{array}{l}\text { Positive } \\
\text { Affective } \\
\text { States }\end{array}$} & I. Cheerful & $6.0(5.0-10.0)$ & $8.0(5.0-11.0)$ & $8.0(5.0-11.0)$ & $8.0(5.0-11.0)$ & $0.000(1)<(2)(3)(4)$ \\
\hline & II. Capable & $10.0(7.0-12.0)$ & $7.0(5.0-10.0)$ & $7.0(5.0-10.0)$ & $7.0(5.0-10.0)$ & $0.000(1)>(2)(3)(4)$ \\
\hline & III. Confident & $5.0(5.0-8.0)$ & $5.0(5.0-8.0)$ & $5.0(5.0-9.0)$ & $5.0(5.0-8.0)$ & \\
\hline & IV. Calm & $5.0(5.0-8.0)$ & $7.0(5.0-10.0)$ & $7.0(5.0-10.0)$ & $6.0(5.0-10.0)$ & $0.000(1)<(2)(3),(3)>(4)$ \\
\hline \multirow{3}{*}{$\begin{array}{l}\text { Negative } \\
\text { Affective } \\
\text { States }\end{array}$} & V. Depressed & $10.0(7.0-12.0)$ & $8.0(5.0-11.0)$ & $8.0(5.0-10.0)$ & $8.0(5.0-10.0)$ & $0.000(1)>(2)(3)(4)$ \\
\hline & VI. Ashamed & $10.0(7.0-12.0)$ & $10.0(6.0-12.0)$ & $10.0(7.0-12.0)$ & $10.0(6.0-12.0)$ & $0.002(1)>(2)$ \\
\hline & VII. Tense & $15.0(12.0-17.0)$ & $11.0(8.8-15.0)$ & $11.0(8.0-15.0)$ & $11.0(8.8-15.0)$ & $0.000(1)>(2)(3)(4)$ \\
\hline
\end{tabular}

$\mathrm{n}=258$; median (25\% - 75\% tile); Friedman test, Bonferroni method.

The "confident" score showed no difference among the four colors.

\subsection{Common Impressions of Hazmat Suits by Age Groups}

To compare the impressions of hazmat suits, the participants were additionally classified into two groups: participants in their 20s and those in their 30 s and older. For all the colors, there was no significant difference in positive affirmative state scores between two groups. However, for some colors, there was a difference in the "ashamed" and "tense" scores. Specifically, the "ashamed" score for $\mathrm{W}$ was $10.0(8.0-13.0)$ and $10.0(7.0-11.0)$ in the participants in their $20 \mathrm{~s}$ and those in their 30s and older, respectively; the "ashamed" score for P was 10.0 (7.0 - 12.0) and $9.0(5.0$ - 12.0) in the participants in their $20 \mathrm{~s}$ and the participants in their 30s and older, respectively; the "tense" score for G was 12.0 (9.0 $15.0)$ and $10.0(8.0$ - 15.0) in the participants in their 20s and the participants in their 30s and older, respectively; the scores for the participants in their 20s were significantly higher than those for the participants in their 30s and older $(\mathrm{p}<$ $0.05)$.

\subsection{Common Impressions of Hazmat Suits by the Experience of Radiation Survey}

The participants were classified into two groups according to their experience (if they had ever undergone a radiation survey), in order to compare their impression of hazmat suits by color. No significant differences were found in the impressions for hazmat suits in W, I, and G between the two groups. However, the "capable" score for the hazmat suits in P was 7.0 (5.0 - 10.0) and 5.0 (5.0 - 7.0) in the participants with and without the experience, respectively; the scores of the participants with the experience of undergoing the survey was significantly higher $(\mathrm{p}<0.010)$. Similarly, the "depressed" score for hazmat suits in $\mathrm{P}$ was 9.0 $(5.0-10.0)$ and $6.0(5.0-8.0)$ in the participants with and without the experience, respectively; the scores of the participants with the experience of undergoing the survey was significantly higher $(\mathrm{p}<0.025)$. 


\section{Discussion}

It has been pointed out that there are sex differences in color impressions [14] [15] [16]. However, in this study, no sex differences were found in the color of the radiation hazmat suit. When age groups were compared, some affirmative states showed a difference, while many affirmative states did not. In the results of a study by Albert et al. [17], the young generation showed lower and higher likability for white nursing clothes and for bold-print-top/blue pressed pants. They reported that there was a generational difference in impressions of the color and the design of the uniform. There was no difference between the age groups in our study, which suggests that there was a common impression for radiation hazmat suits regardless of the difference of sex and age.

The "capable" score for conventional radiation hazmat suits in W (white) was higher than the scores for other colors, which might be associated with an expressed role expectation for radiation survey as special work. White is the most common color for uniforms of health professionals, which may be related to the impression that health professionals wearing a white robe must provide appropriate responses. In a survey of patient perceptions of nurse attire in adult patients by Porr et al. [18], white nurse attire showed higher scores regarding professional items than did the scores for other colors and designs. Similarly, in a survey performed with adults by Albert et al. [17], white nurse uniforms showed higher scores regarding professional items; in a study performed in patients in the department of psychiatry by Küçük et al. [19], the highest response for the expected color of nurses' uniforms was white (33.9\%) because it was comforting; this finding is supported by the result of our study that the "capable" score for $\mathrm{W}$ was higher than that score for I, P, and G.

On the other hand, the results of our study showed low "cheerful" and "calm" scores for white hazmat suits and high "depressed" and "tense" scores. Based on these results, examinees' tension may be increased by the setting of the radiation survey, which may provoke oppressive feelings. In a study performed in school-aged patients by Albert et al. [20], the positive affirmative state scores and negative affirmative state scores for white nurses' uniforms were low and high, respectively. They also reported that the uniform with a bold pink print showed a high "pleasant and nice" score. In other words, white radiation hazmat suits, which provoke feelings of tension in examinees, are not preferable. In addition, considering the facts that the "calm" score for W was approximately similar to that for G, it can be said that hazmat suits in green, just like those in white, are not desirable.

Since in comparison to $\mathrm{W}$, the positive and negative affirmative states were higher and lower for I and P, respectively, these two colors can be considered as desirable colors for hazmat suits used for radiation surveys. In a study by Fukazawa et al. [12], ivory was a favorable color that provides calmness to patients' minds and bodies.

In an analysis of the impressions based on experience of undergoing a radia- 
tion survey, the hazmat suits in $\mathrm{P}$ (salmon pink), which provided relatively good impressions, showed a high "depressed" score. Based on these results, it can be surmised that feelings of anxiety and tension caused by radiation survey were more likely to provide a far greater influence on examinees than one might have imagined. Results of this study are expected to further improve radiation hazmat suits. This study suggests that ivory and salmon pink are more desirable colors for hazmat suits than is white for radiation surveys.

\section{Conclusions}

The following common impressions of radiation hazmat suits were obtained from the survey performed with a total of 258 participants.

1) There were no sex differences in the common impressions of radiation hazmat suits.

2) For white radiation hazmat suits, a high score reflecting the degree of "capable" was obtained while the "cheerful" score and the "calm" score were low and the "depressed" score and the "tense" score were high.

3) The colors that showed the highest score for "calm" were I and P.

4) The "ashamed" score reflecting the impression for $\mathrm{W}$ and $\mathrm{P}$, and the "tense" score reflecting the impression for $\mathrm{G}$, were higher for participants in their 20s than for those in their 30s and older.

\section{Limitations of This Study}

It is impossible to generalize the results of this study because the sample size was small and there was an uneven distribution of sex and age groups. In addition, the impressions of colors may be based on participants' previous impressions, and changing the color of the hazmat suits may only change impressions until people become accustomed to those suits.

\section{Acknowledgements}

We gratefully acknowledge all the participants who cooperated in this study.

\section{Fund}

This work was supported by JSPS KAKENHI Grant Number JP15K11545.

\section{Conflicts of Interest}

The authors declare no conflicts of interest regarding the publication of this paper.

\section{References}

[1] Jin, L., Park, P.K., Hond, K.A. and Yoon, K.J. (2015) Effect of Aluminized Fabrics on Radiant Protective Performance of Fire Proximity Suit Materials. Annals of Occupational Hygiene, 59, 243-252.

https://academic.oup.com/annweh/article/59/2/243/2740586 
[2] Kong, P.W., Suyama, J., Cham, R. and Hostler, D. (2012) The Relationship between Physical Activity and Thermal Protective Clothing on Functional Balance in Firefighter. Research Quarterly for Exercise and Sport, 83, 546-552.

https://www.ncbi.nlm.nih.gov/pmc/articles/PMC4895198/ https://doi.org/10.1080/02701367.2012.10599144

[3] Gonzalez, R.R., McLellan, T.M., Withey, W.R., Chang, S.K. and Pandolf, K.B. (1997) Heat Strain Models Applicable for Protective Clothing Systems: Comparison of Core Temperature Response. Journal of Applied Physiology, 83, 1017-1032. https://www.physiology.org/doi/pdf/10.1152/jappl.1997.83.3.1017 https://doi.org/10.1152/jappl.1997.83.3.1017

[4] Costello, J.T., Stewart, K.L. and Stewart, I.B. (2015) Inside the "Hurt Locker": The Combined Effects of Explosive Ordnance Disposal and Chemical Protective Clothing on Physiological Tolerance Time in Extreme Environments. Annals of Occupational Hygiene, 59, 922-931. https://doi.org/10.1093/annhyg/mev029 https://academic.oup.com/annweh/article/59/7/922/2196094

[5] Tokizawa, K., Sawada, S., Oka, T., Yasuda, A., Tai, T., Ida, H. and Nakayama, K. (2014) Fan-Precooling Effect on Heat Strain While Wearing Protective Clothing. International Journal of Biometeorology, 58, 1919-1925. https://link.springer.com/content/pdf/10.1007\%2Fs00484-014-0794-8.pdf https://doi.org/10.1007/s00484-014-0794-8

[6] Borg, D.N., Stewart, I.B. and Costello, J.T. (2015) Can Perceptual Indices Estimate Physiological Strain across a Range of Environments and Metabolic Workloads When Wearing Explosive Ordnance Disposal and Chemical Protective Clothing? Physiology \& Behavior, 147, 71-77. https://doi.org/10.1016/j.physbeh.2015.04.018 https://www.sciencedirect.com/science/article/pii/S0031938415002139?via\%3Dihub

[7] Nishizawa, Y., Noto, Y., Kitamiya, C. and Aizu, K. (2014) Nursing Students and Nurses' Hazmat Suit Impressions. The Journal of Radiological Nursing Society of Japan, 2, 29-34. (In Japanese) http://www.rnsj.jp/web/journal/0201/pdf/2005.pdf

[8] Fujishima, M. (2000) Japanese Society of Hypertension Guidelines for the Management of Hypertension (JSH 2000). Diagnosis and Treatment of Hypertension, 29, 52-57. (In Japanese)

[9] Okazaki, Y. and Miyajima, T. (2008) Influence of the Colors White, Blue, Green on the Body (Circulatory Dynamics) and Psychology of Patients. Medical and Bilogy, 152, 443-449. (In Japanese)

[10] Roohafza, H., Pirnia, A., Sadeghi, M., Toghianifar, N., Talaei, M. and Ashrafi, M. (2009) Impact of Nurses Clothing on Anxiety of Hospitalised Children. Journal of Clinical Nursing, 18, 1953-1959. https://doi.org/10.1111/j.1365-2702.2008.02745.x https://onlinelibrary.wiley.com/doi/epdf/10.1111/j.1365-2702.2008.02745.x

[11] Sato, E., Kudo, S., Ogura, N. and Kobayashi, A. (2005) Current Status of the Color Environment in Medical Facilities and Awareness of Patients and Nurse about It. Bulletin of Health Sciences Hirosaki, 4, 51-59. (In Japanese) http://www.hs.hirosaki-u.ac.jp/kouhou/hg/web/pdf/HEALTHSCIENCESHIROSAK I_Vol.4.pdf

[12] Fukazawa, K., Takataya, K. and Sato, T. (2009) Physiological and Emotional Response of Healthy Adults to Colors. Yamanashi Nursing Journal, 8, 23-27. (In Japanese)

http://opac.lib.yamanashi.ac.jp/opac/repository/1/28731/YNJ8-1-023to027.pdf

[13] Saito, E., Nakagawa, S. and Fujiwara, Y. (1995) Construction of the Scale for Measurement of Multiple Affective States Generated by Dressing. Journal of the Textile Machinery Society of Japan, 48, 105-112. (In Japanese) 
[14] Ohmori, N. and Wada, Y. (2009) Gender Differences in Color Preference and the Psychological Effect of Color. The Bulletin of Health Science University, 5, 67-76. (In Japanese) https://ci.nii.ac.jp/els/contents110009323681.pdf?id=ART0009884718

[15] Saito, E. and Nakagawa, S. (1996) Differences in Images of Clothes Expressing Masculinity and Femininity between Male and Female. Journal of the Textile Machinery Society of Japan, 49, 212-221. (In Japanese) https://doi.org/10.4188/transjtmsj.49.8_T212

[16] Oyama, T. (1997) Perception of Colors and Their Psychological Effects. Journal of the Visualization Society of Japan, 17, 2-7. (In Japanese)

[17] Albert, N.M., Wocial, L., Meyer, K.H., Na, J. and Trochelman, K. (2008) Impact of Nurses' Uniforms on Patient and Family Perceptions of Nurse Professionalism. Applied Nursing Research, 21, 181-190.

https://www.sciencedirect.com/science/article/pii/S089718970700064X?via\%3Dihub

[18] Porr, C., Dawe, D., Lewis, N., Meadus, R.J., Snow, N. and Didham, P. (2014) Patient Perception of Contemporary Nurse Attire: A Pilot Study. International Journal of Nursing Practice, 20, 149-155.

https://onlinelibrary.wiley.com/doi/epdf/10.1111/ijn.12160

[19] Küçük, L., Çömez, T., Kaçar, S., Sümeli, F. and Taşkıran, Ö. (2015) Psychiatric Patients' Perspective: Nursing Uniforms. Archives of Psychiatric Nursing, 29, 383-387. https://www.psychiatricnursing.org/article/S0883-9417(15)00138-7/pdf

[20] Albert, N.M., Burke, J., Bena, J.F., Morrison, S.M., Forney, J. and Krajewski, S. (2013) Nurses' Uniform Color and Feelings/Emotions in School-Aged Children Receiving Health Care. Journal of Pediatric Nursing, 28, 141-149. https://www.sciencedirect.com/science/article/pii/S0882596312001303?via\%3Dihub 